\title{
EDITORIAL
}

\section{In this Issue: Access to Care, Spirituality, and Relevant Research}

\author{
Kurt C. Stange, $M D, P b D$, Editor
}

Ann Fam Med 2008;6:386-387. DOI: 10.1370/afm.897.

rticles in this issue address diverse aspects of
access to care, spirituality, and making research
relevant.

\section{ACCESS TO CARE}

The study by Rittenhouse and colleagues examines the association between attending a medical school funded by the US government's Title VII primary care training grant program and 2 markers of practicing in a setting dedicated to caring for patients and populations that would otherwise be underserved. ${ }^{1}$ The finding that Title VII supports the training of physicians who are more likely to staff Community Health Centers and participate in the National Health Service Corps could be in part due to selection factors of who attends these medical schools, but it also implies a possible effect of Title VII in increasing access to care for vulnerable populations.

China, facing growing disparities in health and health care, is embarking on a major reemphasis on primary care. The study by Yang et al provides a snapshot of the staffing and service delivery of community health services as China embarks upon this transition. $^{2}$

The study by Farley et al examines the feasibility of increasing access to diabetic retinopathy screening by training community health center primary care physicians to read retinal photographs taken in the clinics. ${ }^{3}$ This is an excellent example of a practice network implementing a new program, rigorously evaluating it, and then sharing the findings in a way that advances transportable knowledge and points the way for others.

An analysis of data from the COMBINE trial of naltrexone and acamprosate with medical management for alcohol dependence examines patient and clinician factors associated with treatment outcomes. ${ }^{4}$ Although the identified patient and clinician factors may have implications for increasing access to care for intensive alcohol dependence treatment, the conduct of the study at sites associated with alcohol treatment centers raises caution in transporting these findings to other settings where motivation, available expertise, and resources may be lower.

A methodology study compares the HearingDependent Daily Activities Scale with a standardized audiogram. ${ }^{5}$ By helping to identify the impact of hearing loss on the daily life of elderly patients, this instrument may be useful in tailoring access to audiology services.

The article featured in this issue's Annals Journal Club shows how access to home blood pressure monitoring can provide better patient stratification for mortality risk than just using office blood pressures. ${ }^{6}$ These findings may be useful in tailoring the aggressiveness of therapy and call for trials of stepped approaches to hypertension management that include home blood pressure monitoring. ${ }^{7}$

\section{SPIRITUALITY IN HEALTH CARE}

Related to the access-to-care theme, a study by Daaleman et al of spiritual care at the end of life discovers the importance of being present-physically, temporally, and with openness-to the patient's life course. $^{8}$

Katerndahl examines outcomes associated with spiritual "symptoms" that include peacefulness, harmony, meaning, and sense of purpose. ${ }^{9}$

An expansive conceptual framework presented by Anandarajah provides both secular and religious pathways for assimilating somatic, mental, spiritual, environmental, social, and transcendent factors into clinical care. ${ }^{10}$

An editorialist reflects on these 3 studies, making a case for studying the biological mechanisms of spiritual phenomenon. This perspective represents the dominant scientific paradigm upon which these 3 studies attempt to expand. ${ }^{11}$ 


\section{MAKING RESEARCH RELEVANT}

Two essays contribute unique perspectives on making research relevant for practice. Kottke et al present a framework for optimizing practice through research. ${ }^{12}$ Sussman and Rivera describe an approach to engaging communities in research by eliciting and interpreting a story told by a respected local leader. ${ }^{13}$ Together, these essays point toward engaging both communities of practice and the communities in which practice is nested in the generation of relevant new knowledge.

Please share your insights by joining the Annals online discussion at http://www.AnnFamMed.org.

\section{References}

1. Rittenhouse DR, Fryer GE Jr, Phillips RL Jr, et al. Impact of Title VII training programs on community health center staffing and National Health Service Corps participation. Ann Fam Med. 2008;6(5):397-405

2. Yang J, Guo A, Wang Y, et al. Human resource staffing and service functions of community health services organizations in China. Ann Fam Med. 2008;6(5):421-427.

3. Farley TF, Mandava N, Prall FR, Carsky C. Accuracy of primary care clinicians in screening for diabetic retinopathy using single-image retinal photography. Ann Fam Med. 2008;6(5):428-434.

4. Ernst DB, Pettinati HM, Weiss RD, Donovan DM, Longabaugh R. An intervention for treating alcohol dependence: relating elements of medical management to patient outcomes with implications for primary care. Ann Fam Med. 2008;6(5):435-440.
5. López-Torres Hidalgo J, Boix Gras C, Téllez Lapeira J, et al. The Hearing-Dependent Daily Activities Scale to evaluate impact of hearing loss in older people. Ann Fam Med. 2008;6(5):441-447.

6. Dawes MG, Bartlett G, Coats AJ, Juszczak E. Comparing the effects of white coat hypertension and sustained hypertension on mortality in a UK primary care setting. Ann Fam Med. 2008;6(5):390-396.

7. Pickering TG, Miller NH, Ogedegbe G, Krakoff LR, Artinian NT, Goff D. Call to action on use and reimbursement for home blood pressure monitoring: a joint scientific statement from the American Heart Association, American Society of Hypertension, and Preventive Cardiovascular Nurses Association. J Cardiovasc Nurs. 2008;23(4):299-323.

8. Daaleman TP, Usher BM, Williams SW, Rawlings J, Hanson LC. An exploratory study of spiritual care at the end of life. Ann Fam Med. 2008;6(5):406-411.

9. Katerndahl DA. Impact of spiritual symptoms and their interactions on health services and life satisfaction. Ann Fam Med. 2008;6(5):412-420

10. Anandarajah $\mathrm{G}$. The $3 \mathrm{H}$ and BMSEST models for spirituality in multicultural whole-person medicine. Ann Fam Med. 2008;6(5):448-458.

11. Davidson RJ. Spirituality and medicine: science and practice. Ann Fam Med. 2008;6(5):388-389.

12. Kottke TE, Solberg LI, Nelson AF, et al. Optimizing practice through research: a new perspective to solve an old problem. Ann Fam Med. 2008;6(5):459-462.

13. Sussman $A L$, Rivera $M$. 'Be gentle and sincere about it': a story about community-based primary care research. Ann Fam Med. 2008;6(5):463-465 